\section{Category}

Metal-Catalyzed Asymmetric Synthesis and Stereoselective Reactions

\section{Key words}

\section{rhodium}

bisphosphine ligands

\section{2-pyridones}

C. LI, M. KÄHNY, B. BREIT* (ALBERT-LUDWIGS-UNIVERSITÄT FREIBURG, GERMANY) Rhodium-Catalyzed Chemo-, Regio-, and Enantioselective Addition of 2-Pyridones to Terminal Allenes Angew. Chem. Int. Ed. 2014, 53, 13780-13784.

\title{
Enantioselective Rhodium-Catalyzed Allylation of 2-Pyridones
}

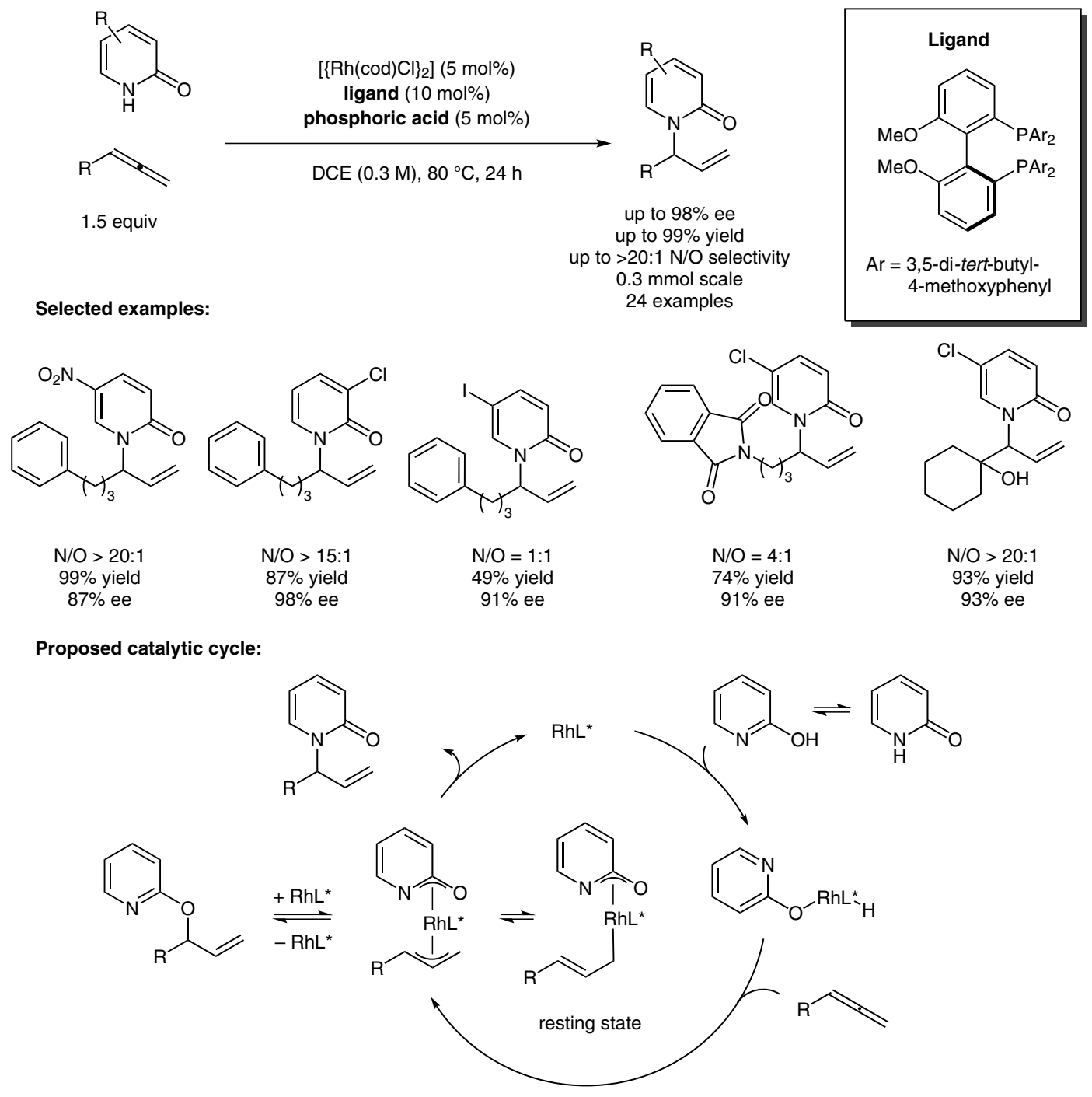

Significance: Enantioenriched N-substituted 2pyridones are an important class of biologically active molecules. Their synthesis has been described starting from chiral electrophiles (Y.-Q. Fang et al. J. Am. Chem. Soc. 2010, 132, 15525) and chiral amines (Y. Yu et al. J. Nat. Prod. 2013, 76, 2226). The authors report a chiral allylation strategy beginning from 2-pyridones and allenes.
Comment: Almost all substrates preferred $\mathrm{N}$-alIylation over O-allylation, except the 5-iodopyridone substrate. A 1:1 mixture of N/O-allylated products was observed in this case. Substitution on the allene component was also tolerated, including a tertiary alcohol. A decrease in N/O selectivity was observed for the substrate with a phthalamido group.

SYNFACTS Contributors: Mark Lautens, Zafar Qureshi 